\title{
An Incidence of Road Mortality in the Asian Water Monitor (Varanus salvator) in Kota Kinabalu, Sabah, Malaysia
}

\author{
Steven J. R. Allain ${ }^{1}$ and Mark J. Goodman ${ }^{2}$ \\ ${ }^{1} 11$ Trafalgar Way, Braintree, Essex, CM7 9UX (steveallain@live.co.uk) \\ ${ }^{2} 69$ Norfolk Street, Cambridge, CB1 2LD (markjamejones@yahoo.com)
}

$\mathrm{T}$ he Asian Water Monitor (Varanus salvator) is a large lizard distributed widely throughout Southeast Asia (Das 2015). It is a strong semiaquatic swimmer that inhabit wetlands, mangrove swamps, and human-altered habitats (Gillespie et al. 2005). Asian Water Monitors, like other species of monitors (Rahman et al. 2015) are highly opportunistic feeders that often exploit any available food source. Unfortunately, due to their relatively large size and habituation to people, monitors like $V$. salvator often are casualties of accidental road mortality (e.g., Jackson and Lemm 2009; Karunarathna et al. 2013). In some areas of Asia, the frequency and density of road mortalities of monitor lizards can be quite high (Parasharya and Tere 2007). Herein we present such a case from Sabah, Malaysia.

On 17 September 2016 at approximately 2120 h, we found a juvenile $V$. salvator dead by the side of the road (Fig. 1) half-way down Jalan Pejabat Pos Besar in Kota Kinabalu, Sabah. The road itself is approximately $180 \mathrm{~m}$ in length and the lizard was on the northwest-bound side of the road toward the intersection with Jalan Tun Fuad Stephen. The individual had a snout-vent length of approximately $25 \mathrm{~cm}$ and a total length of approximately $60 \mathrm{~cm}$. We estimated that the lizard could have only been dead for one to two hours before its discovery. On closer examination, we saw no obvious external
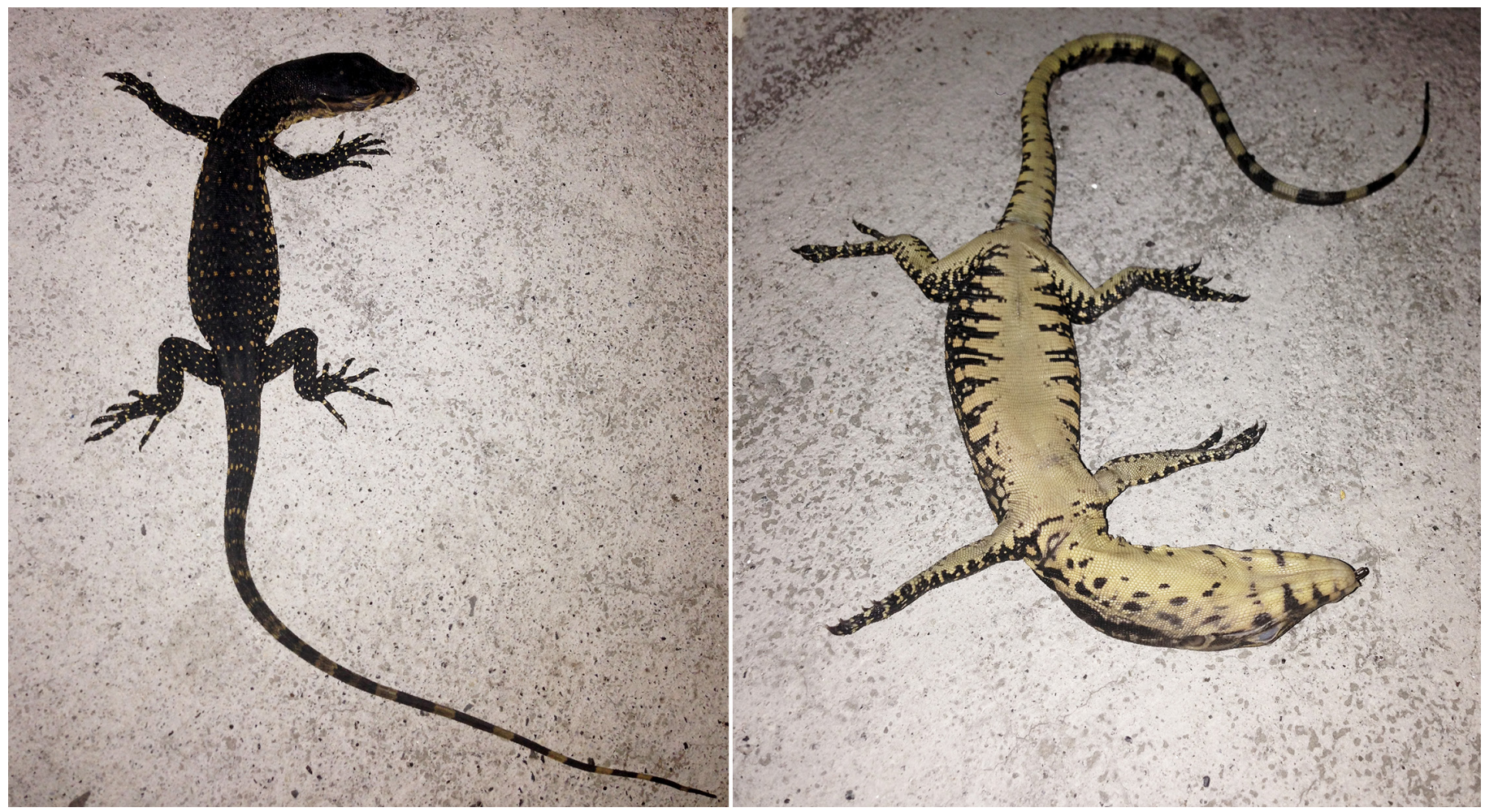

Fig. 1. Dorsal (left) and ventral views of a road-killed Asian Water Monitor (Varanus salvator) found in Kota Kinabalu, Sabah, Malaysia. The dorsal view illustrates the position of the lizard when discovered. 
damage and we were unable to determine the severity of any internal injuries. The body was removed from the road and deposited in a nearby hedge.

Roads fragment habitats and force animals to cross them in order to find food or a mate, and road mortality is a leading cause of decline for some reptilian species, particularly those that live in close proximity to human habitation (Todd et al. 2010). Previous research conducted in India (Kumara et al. 2000) suggested a positive relationship between the rainy season and the frequency of road-killed reptiles. However, elsewhere in India, Sunder (2004) and Bhupathy et al. (2011) found that more reptiles were killed in the dry season. The discrepancies between the various studies are likely due to differences in local habitats and reptilian assemblages. More data are needed to evaluate the effects of road mortality of reptiles in Malaysia.

\section{Literature Cited}

Bhupathy, S., G. Srinivas, N.S. Kumar, T. Karthik, and A. Madhivanan. 2011. Herpetofaunal mortality due to vehicular traffic in the Western Ghats, India: A case study. Herpetotropicos 5: 119-126.
Das, I. 2015. A Field Guide to the Reptiles of South-East Asia. Bloomsbury Publishing, London, UK

Gillespie, G., S. Howard, D. Lockie, and M. Scroggie. 2005. Herpetofaunal richness and community structure of offshore islands of Sulawesi, Indonesia. Biotropica 37: 279-290.

Jackson, R. and J.M. Lemm. 2009. Stomach content note for a road-killed Varanus spenceri. Biawak 3: 18-20.

Karunarathna, D.M.S., S. Henkanaththegedara, A.A. Amarasinghe, and A. de Silva. 2013. Impact of vehicular traffic on herpetofaunal mortality in a savanna forest, eastern Sri Lanka. Taprobanica 5: 111-119.

Kumara, H.N., A.K. Sharma, A. Kumar, and M. Singh. 2000. Roadkills of wild fauna in Indira Gandhi Wildlife Sanctuary, Western Ghats, India: Implications for management. Biosphere Conservation 3: 41-47.

Parasharya, B.M. and A. Tere. 2007. An observation of Common Indian Monitor Lizard Varanus bengalensis Schneider mortality on Anand-Ahmedabad Highway, Gujarat, India. Zoos' Print Journal 22: 2872.

Rahman, K.M., M.M.H. Khan, and I.I. Rakhimov. 2015. Scavenging behavior of the Bengal Monitor (Varanus bengalensis) in Jahangirnagar University Campus, Bangladesh. Journal of Scientific Research and Reports 7: 539-550.

Sunder, K.S.G. 2004. Mortality of herpetofauna, birds and mammals due to vehicular traffic in Etawah District, Uttah Pradesh, India. Journal of the Bombay Natural History Society 101: 392-398.

Todd, B.D., J.D. Willson, and J.W. Gibbons. 2010. The global status of reptiles and causes of their decline, pp. 47-67. In: D.W. Sparling, G. Linder, S. Bishop, and S. Krest (eds.), Ecotoxicology of Amphibians and Reptiles. 2nd Edition. CRC Press, Pensacola, Florida, USA. 